\title{
Diagnosing Patients and Recommending mHealth Technology? Exploring Physicians' Intention to Influence Patients' Use of Self-Health Management Technology
}

\author{
Hyeyoung Hah \\ Florida International University \\ hhah@,fiu.edu
}

\author{
Cynthia LeRouge \\ Florida International University \\ clerouge@fiu.edu
}

\begin{abstract}
This paper introduces a new type of IT role, IT influencers. We define IT influencers as persons whose decision-making is critical but who do not directly use the focal technology. Then we contextualize the social role of IT influencers within the unified theory of acceptance and use of technology (UTAUT) framework to explore the conditions under which such individuals demonstrate IT-directed social behavior, termed intention to influence and become a social influence upon the targeted user's technology use. We look at physicians, as IT influencers, and chronic diabetic patients, as IT users, who work together to promote patients' self-management of chronic diabetes using mobile health (mHealth) technology. The results demonstrated that physicians' evaluation of both IT and patients' technical ability led to intention to influence patients' use of mHealth technology. Furthermore, intent to influence is promoted in a social context in which supporting resources are available for both IT users.
\end{abstract}

\section{Introduction}

This paper introduces a new introduces a new type of IT role - IT influencers and such users' IT-directed, social behavior, termed intention to influence. While many stakeholders are involved in various contexts of technology use in practice, most of the attention in information systems (IS) studies is on the primary users' IT use behavior. In response, this paper explores another important IT user group, IT influencers, whose decisionmaking is critical but who do not directly use the focal technology. Throughout this paper, we view IT influencers as those who share the same goals with and make important decisions on behalf of primary IT users and endorse the use of the focal technology then further examine their pivotal role in affecting primary IT users' technology use. Intention to influence is particularly relevant in the healthcare context, where an increasing number of technologies are designed to support self- management by individual health consumers between visits with their doctors.

Generally speaking, technologies ranging from internet banking, grocery checkout kiosks, hotel and airline booking to management of personal health records online, require self-autonomy and selfmanagement of tasks on the part of the IT users [1]. Given that these "self-management" technologies are part of organizational business processes, it is likely that there are related users on the other end of the selfmanagement system who are often treated as nominal or nonexistent [2]. For example, when technology users use a checkout kiosk in a retail store, they expect the presence of store employees in case of system failures [3]. However, sometimes adoption and use of such selfmanagement technology can be delayed because there might be a discrepancy between what consumers view as self-management technology and what managers or frontline employees perceive $[4,5]$. In healthcare, physicians and patients might be in such a relationship that patients expect physicians' inputs when using health information technology (HIT) to manage their conditions while at home $[6,7]$.

Such introduction of self-management technologies are redefining the role of physicians in healthcare. Selfmanagement technologies in healthcare or self-care technologies have been viewed as enablers of understanding, monitoring, and controlling their chronic health conditions [84]. Along with advances in wearable technology, online or mobile health records that tailor multi-stakeholders' goals and tasks, there have been growing demands for frontline clinicians' knowledge of self-care technologies to recommend adequate technologies to provide patient-centered care plans and regimen. Although practitioners, and academics jointly emphasize their active involvement in the development and adoption of in-house [14] as well as commercial health technologies [64], healthcare providers' ability of recommending health information technology (HIT) to patients has been implicitly assumed in the use context of self-management technology. 
Moreover, while prior IS literature has noted the importance of the influence of others (or social influence) in various technology use contexts, whether and how such others become a source of social influence is largely underexplored. As technology use is often realized in a social context, there are groups of individuals on the continuum of IT use whose attitudes, statements, and behaviors become a social influence that affects the focal users' technology use [8]. However, attention has been paid to primary IT users' IT-directed behavior in existing IS studies while regarding the surrounding or secondary users as nominal social users [9], onlookers [10,11], reference users [12], or part of team practice [13]. Thus far, the subject of whether and how secondary users (or IT influencers) become a social influence to influence the primary users' technology use for better task performance has been explored less frequently.

To fill this gap, we extend the UTAUT theory to a "social" dyad between primary IT users and IT influencers by considering mechanism through which IT influencers are stimulated to influence primary users' technology use, particularly in healthcare. Based on IT influencers' judgments and knowledge of both IT users and the focal technology, we propose that IT influencers can promote or prohibit the primary users' interaction with the focal technology. Furthermore, we identify facilitating conditions that affect the IT influencers' evaluation of the technology and the primary users' technology use capability as two crucial factors that lead to intention to influence. Our research questions are: 1) How do IT influencers' interactions with other IT users and technology affect IT influencers' behavioral intention? and 2) What are the effects of facilitating conditions for IT influencers to strengthen their social influence on others? To address these questions, we contextualized our UTAUT model at Chinese university hospitals where physicians, as IT influencers, and older patients, as primary IT users, work together to manage chronic diabetes using mobile-based, diabetes selfmanagement technology. A field survey was administered to physicians at the locations where a new mobile diabetic application was piloted for older patients.

\section{Theoretical background}

The well-known theory of UTAUT has regained its popularity in healthcare research to understand various types and roles of IT users when performing personal, shared, or organizational tasks [14]. UTAUT acknowledges direct and indirect effects of key factors to explain individual users' acceptance and use of the new IT [9]. One of the unique aspects of the UTAUT model is that the existence and influence of others is defined as social influence and regarded as a key factor influencing individual users' IT use. Researchers have extensively examined this theory across numerous business contexts [14-16]. In a recent notable article, Venkatesh and colleagues summarized the application, integration, and extension of the UTAUT model. They discussed how the path of key influential antecedentsattitudes-behavioral intention could be either moderated or mediated by situation-specific contextual moderators [17]. Viewing an IT use context as social helps explain a new pattern of acceptance and use of IT by a network of supportive relationships [18]. Since social context is the place where "social expertise" and "collective knowledgeability" are related and co-exist (p. 602) [19], social norms and expectations established by others may implicitly or explicitly constrain the focal individual users' IT use behavior (pp. 232,233) [18, 20]. In other words, as IT users' behaviors are situated in a particular physical or conceptual place [19], expectations of others and a personal desire for their approval can channel the focal individuals' IT use behaviors [21].

Given that organizations have been regarded as social contexts where multiple constituents socially interact with people and organizational IT, individuals' creativity and innovative behavior have been facilitated or impeded within organizational contexts [22, 23]. Across organizational contexts, a technology and individuals' interactions with the focal IT are defined differentially, and therefore, the use of technology is affected by what is used (scope) and who uses the focal technology within the organization (role) [24]. While the scope of organizational IT varies, the role of IT is related to who uses it on the continuum of IT use spectrum. Prior studies noted a group of individuals related to the use of an IT but who do not actually use the IT within the designated context. According to Fulk et al. (1990), this network of IT users can be categorized as "modelers" and "observers" whose attitudes and behavior will converge by the complex interplay of behavior based on cognition, judgment, and attitudes of modelers [25]. Namely, what "important" others think, use, and their position of authority affects the other individuals' technology-related behaviors [17]. Thus, individuals' IT use behavior is formed by observing "what others do" under these social circumstances.

As such, social contexts can determine who becomes modelers or observers of IT use. As interactions and sensemaking of IT use are embedded within the social contexts, such contextual characteristics help shape the way individuals learn [26] and process social information when employing IT [20]. 
For example, prior studies have noted that one's willingness to use IT is determined by "his or her personal evaluation of the action and by the social pressure to act" (p.229) [21]. In this case, modelers' behaviors channel observers' attitudes and learning of IT use [27] in that the one who directly uses IT can spread their influence on observers within that context. In addition, IT users can influence one another socially via a network of family members of friends, secondary sources (such as the news media), co-workers, or member influence [28]. Namely, modelers and observers all together can influence one another in the social context of IT use.

However, the role and impact of "observers" have assumed nominal or fixed in existent IS literature. "Observers" are part of the interactions with others, and their "attitudes toward and uses of technologies converge in social systems (p.921)" [29]. From the perspective of modelers, others have been "socially proximal referents." Along with various social contexts, "others" have been either those who are actively involved in others' technology use or reference users who are implicitly present in the technology use context. Recent IS studies have begun looking at the role and impacts of observers on modelers' technology use. On an individual level, IT influencers are described as onlookers (e.g., [10]) or reference users (e.g., [11]) who do not directly use the technology. Still, their use is visible to the focal users. On a group level, IT influencers exist inside the group such that a group's positive or negative feelings (e.g., [30]) or possible options from the use of technology (e.g., [31]) can influence group-based decision-making within an automotive engineering unit [31] or a surgical team [10]. The emerging theme from these studies is that observers can also influence "modelers" depending upon their defined roles within the social context. Still, the extent to which others become a source of social influence is underexplored.

Taken together, we call for more attention to the unique attitudes and behavior of others or IT influencers in a social context. From the theoretical lens of social influence, we highlight the role of IT influencers in predicting primary users' IT use within the social organizational context and examine the mechanism of how IT influencers' social influence works in a nomological network. Individual users have differential perceptions of technology, and such variances generally translate into contrasts in technology use patterns in social contexts [2, 8]. Although peer or superior influence has been a determinant of social norms [32], the extent to which the social influence of others takes place has been implicitly assumed but not explicitly tested. Recent studies have spotlighted the role of IT influencers in explaining primary users' IT use within a functional unit or an organization. However, the mechanisms through which IT influencers become a social influence to support others' IT use remain underexplored. Therefore, we propose a new type of IT observers as IT influencers, whose role is to co-create goals for shared tasks using IT, and yet they are not the actual IT users within a social context.

\section{Research model}

As the objective of this study is to understand the mechanism through which IT influencers willing to support others to use IT for the performance of shared tasks, our key research constructs reflect IT influencers' attitudes and intentions within a social context. First, as a dependent variable, the intention to influence construct is a formative measure that captures IT influencers' intention to influence primary users' technology use [28]. Second, IT influencers' attitude constructs are formative measures reflecting the assessment of the focal technology and the primary users' attitudes toward the technology [9]. Lastly, facilitating conditions are reflective measures that present contextual-specific organizational resources for IT influencers. In our research context, such facilitating conditions include a standardized assessment tool of Health IT to manage chronic disease better and provide a road map for incorporating expected roles of patients and their families, care providers, and community partners $[45,46]$. Figure 1 presents our research model.

\section{Hypothesis development}

In this section, we propose and contextualize our research hypotheses. Focal research variables are as follows: IT use context as antecedents, assessment of the new technology, other users' attitude as mediating variables, and intention to influence as a dependent variable. Figure 1 presents the proposed research model of this study.

\subsection{Intention to influence}

First, we define IT influencers' intention to influence primary users' technology use to complete shared group tasks as the intention to influence. Bagozzi and Lee (2000) have identified two levels of behavioral intentions such that "I-intention" is framed when performing individual tasks or group tasks while "We- 
Contextual Facilitating Conditions

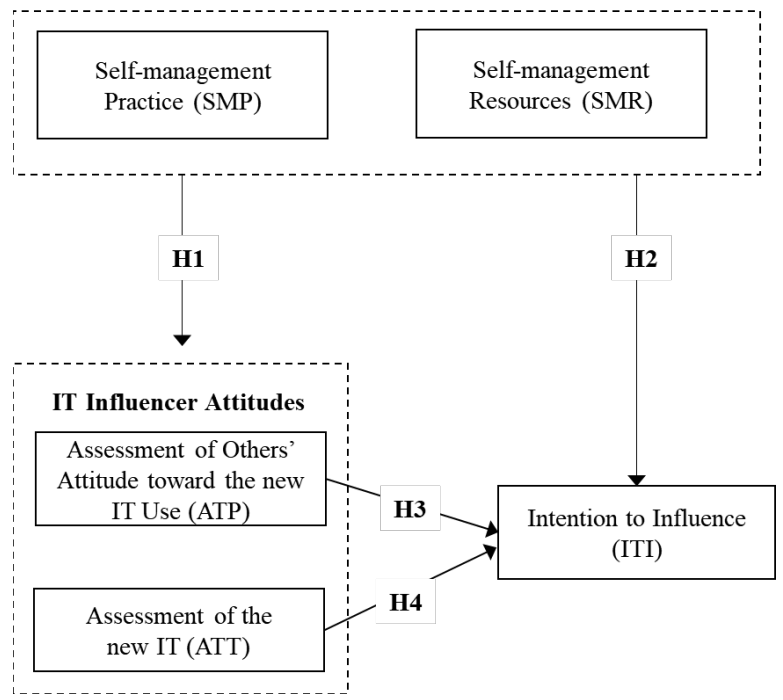

Figure 1. Research model of this study

intention" is framed when performing a group task (see [21] for more categorizations of behavioral intentions). Specifically, We-intention is influenced by individual reasons (e.g., attitudes), interpersonal pressure, group norms, and social identity, all of which are related to performing a group act. Given that these individuals attempt to identify "successful applications of IT that may optimize task performance or organizational processes" [23], we believe the IT influencers' intention to influence can be formed when performing a group task. In our research context, IT influencers attempt to identify the usefulness of the focal mobile health (mHealth) technology to co-manage chronic diabetes with patients. Since IT influencers function based on the shared goals for other users' behavior, they make inferences and form judgments by "registering and interpreting the hints in a broader context, to link them to what they know about the users, technologies, and usage and, thus, form an opinion about the users' behavior in relation to the work practice" (p. 1166)[10]. Therefore, we conceptualize intention to influence as a We-intention where external stakeholders' use of IT is observed and evaluated.

\subsection{Facilitating conditions affecting IT influencers' attitudes and intention to influence}

Facilitating conditions are "the degree to which an individual believes that an organizational and technological infrastructure exists to support use of the system (p.453)" [9]. These have been among the key contextual factors arising from a specific context that help predict primary IT users' attitudes toward IT use and future performance. As individual IT users need cognitive and situational resources in using new IT [47], IT influencers also need organizational resources to form social influence and further support others' IT use. Stakeholder theory provides an adequate theoretical foundation for understanding how IT users receive organizational resources and whether such reception influences their engagement in organizational initiatives. Generally, stakeholders are defined as "all those who can affect or are affected by the achievement of organizational objectives" [48-50]. Prior studies have distinguished stakeholders from other affected or interested parties in the sense that stakeholders are generally capable of positively or negatively influencing organizations in case their needs are not fulfilled [51]. In general management settings, consumers are viewed as the foremost stakeholders, and therefore, the management of stakeholders is a means or required obligation for an organization [48]. Examples of external stakeholders include customers and shareholders or bondholders, whereas CEOs, boards of directors, and strategic business units epitomize internal stakeholders. It can be seen that when consumers' needs are aligned with organizational strategies, they are willing to support these strategies [52]. In our research context, IT influencers (internal stakeholders), working on behalf of the focal organization, attempt to support health consumers' IT use and task execution (external stakeholders). Therefore, organizational resources can be specified for internal stakeholders and external stakeholders, all of which facilitate the attitudes and behavior of IT influencers to meet organizational goals and initiatives.

Throughout this paper, we identify two contextualized facilitating conditions that can, directly and indirectly, influence IT influencers' attitudes and behavioral intention. Our research sites, Chinese hospitals, have adopted a standard assessment tool provided by WHO [45]. Under this universal chronic care model, healthcare organizations are responsible for supporting multi-stakeholders expected roles in treating and managing chronic diseases while managing health consumer technologies [14]. For internal stakeholders such as physicians, organizational resources - including well-integrated health information systems, patient care strategy, or knowledge sharing - can support physicians in helping patients who are managing their diabetes. For external stakeholders (i.e., patients and caregivers), healthcare organizations provide patient education programs to assist in setting goals and involving family members or caregivers. Under the circumstances, physicians' supporting behavior is bound by self-care management practice and available resources within the organizations. As delegates of healthcare institutions, physicians may feel pressure from the management 
guides and regulations to meet these expectations and gain approval from their institutions. Therefore, we hypothesize that organizational resources supporting external stakeholders will positively affect IT influencers' attitudes and behavioral intention:

H1 (a)-(d): Contextual facilitating conditions will be positively associated with IT influencers' evaluation of the users and the technology. $\mathrm{H} 2$ (a)-(b): Contextual facilitating conditions will be positively associated with IT influencers' intention to influence.

\subsection{Assessment of others' attitudes toward the new IT use and intention to influence}

IT users interact with one another to make sense of IT use in a specific context. Here, we define assessment of others' attitudes toward the new IT as IT influencers' evaluation of others' readiness or capability to use the focal IT to perform the shared tasks. In healthcare literature, primary users have been various HIT stakeholders (e.g., [53, 54]), and numerous interactions among the stakeholders have been noted, with limited focus on secondary users. For instance, physicians' informal talks with co-workers can change other coworkers' perspectives on the use of HIT [2] and change their interaction patterns with patients $[55,56]$.

From the perspective of IT influencers in healthcare, doctors need to understand whether the use of the new IT can help patients manage their health between visits; therefore, doctor-patient communication is critical for guided self-health management of chronic illness. Prior studies have determined that patients' levels of health literacy and computer literacy affect the outcome of their healthcare [57-59]. Given the fact that health literacy is likely to be correlated with computer literacy [58], healthcare organizations train care providers in patient-centered communication [60] or provide resources for patient education [57]. Based on this rationale, healthcare providers' assessment of patients' level of understanding of or ability to use new health apps to process health information is associated with their willingness to further recommend the new IT for patients' chronic care management. Likewise, it is critical to correctly assess elderly patients' readiness to use HIT for their chronic care management by physicians in our research context. Therefore, we hypothesize as follows:

H3: IT influencers' assessment of others' attitudes toward the new IT use is positively associated with intention to influence.

\subsection{Assessment of the IT and intention to influence}

Individual users' adoption and use of IT have been studied extensively and have been established using foundational theories, for example, the technology acceptance model (TAM) and the UTAUT $[9,61]$. The premise of these theories is that to achieve expected outcomes or performance, a technology must be used by the focal users [17] and that there are multidimensional interactions among IT users [24, 62] or between users and the technology itself [63]. As social proximity becomes a source of learning, IT influencers' technology-related behaviors and attitudes can be produced in a work setting, increasing the likelihood that attitudes and behavior will converge between modelers and observers $[18,25]$. In a clinician-patient dyad in healthcare, frontline clinicians such as physicians and nurse practitioners perform their roles as "observers" in the process of diagnosing medical symptoms and helping patients to use mHealth technology (e.g., Fitbit, Apple watch, diabetes management app) for chronic care management [64]. Conversely, patients or "modelers" listen to what clinicians explain about their health conditions and might try to converge their behaviors with clinicians' inferences, judgments, or reactions to mHealth technology use. Given that IT influencers in our research context interact with patients in fulfilling shared healthcare tasks where the use of mHealth IT is anticipated, we hypothesize that IT influencers' assessment toward the effectiveness and relevancy of focal IT to manage self-health tasks is likely to promote their intention to influence patients' mHealth IT use. Therefore, we hypothesize as follows:

H4: IT influencers' evaluation of the technology is positively associated with intention to influence.

\section{Methodology}

\subsection{Research setting}

Two university hospitals in China were selected as our research sites, in which provided a context representing whether and how physicians responded to patients' decision to use a mobile health application for chronic disease management. The piloted application, CADA (Chinese aged diabetic assistant), provides an interactive visual tool for aged diabetes patients' selfmanagement of their chronic disease. The adoption and implementation of this application was purely optional for both patients to use and providers to recommend. If a patient opted in, this app would track patients' 
symptoms and provide personalized features for diabetes self-management. Physician's options included whether they would a) encourage patients to use the app in everyday living contexts and b) assist (support) their diabetic patients with treating health symptoms through CADA. Figure 2 presents an example of system interface of CADA technology.

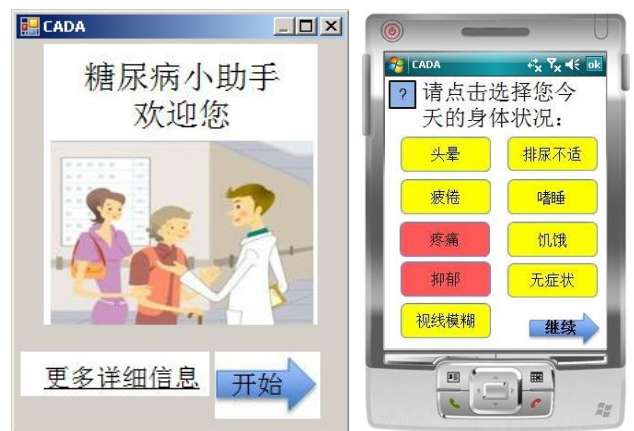

Figure 2. User interface of CADA application

\subsection{Data collection}

We conducted paper-and-pencil surveys physicians with the option to use CADA at two large university hospitals. Surveys were translated into Chinese by the authors and then were edited and proofread by the collaborators at the participating hospitals. Subsequently, the survey instruments and open-ended questions were converted back to English by the principal investigator and the research team. Provided with a CADA information sheet, the providers were surveyed on their opinions of patients' adoption of the proposed CADA system on a 5-point Likert scale (i.e., strongly disagree to strongly agree). In addition, the demographics section of the survey collected anonymous information such as type of practice (e.g., clinic and outpatients, hospital and hospitalized patients), location of practice, and primary patients (e.g., urban or rural). A total of 200 physicians participated in our survey.

\subsection{Measurement development}

For the exogenous constructs, items for selfmanagement practice and self-management resources were adapted from the Innovative Care for Chronic Conditions (ICCC) framework by the World Health Organization (WHO). This framework provides a standardized assessment tool to manage chronic disease better and provide a road map to incorporate the expected roles of patients and their family members, care providers, and community partners [45]. We adopted items that represent a supportive environment, which provides team-based practices and resources for helping patients self-manage their diabetes. For the endogenous constructs, validated items were used to measure attitudes toward technology, assessment of primary users' technology use, and intention to influence, all adapted from Venkatesh et al. (2003) [9]. Attitude toward technology was determined using three items reflecting the physicians' assessment of whether using the focal technology is efficient for patients' diabetes management. Evaluation of primary users' technology use was determined using two items drawn from respondents to evaluate the primary users' intention to employ the focal technology. Lastly, intention to influence was determined by two items to capture IT influencers' intention to guide primary users' employment of technology. The use of two items is consistent with prior IS literature [23, 70].

\subsection{Data Analysis}

The measurement and the structural model were analyzed by PLS-SEM using SmartPLS 3 software. Frequently used in IS literature [9, 23, 34], PLS-SEM is a causal model aimed at maximizing the explained variance of the dependent latent constructs [71]. In this paper, PLS is particularly useful for exploring possible relationships among constructs without known theories and dealing with formative measurement models [72].

Next, with dependent and mediator or moderator data captured from a single source in one instrument, it is recommended that common method bias might threaten the results of this study [73]. To identify this threat, we employed Harman's single-factor analysis, which found that a single factor explains $20.49 \%$ of the variation; thus, common method bias does not threaten the findings of this study.

\section{Results}

First, the measurement models were assessed separately for reflective and formative measures. For reflective measurement models, we assessed convergent validity, discriminant validity, indicator reliability, and composite reliability for the reflective measurement model. For indicator reliability, all item loadings are above the threshold of 0.7 , indicating that more than half of their variance is explained by their substantive latent variable. First, composite reliability is higher than 0.70 , and convergent validity is supported by the average variance extracted, with the value of AVE is greater than 0.5. Furthermore, Attitude toward technology, assessment of primary users' IT use, and intention to influence are all formatively measured. Therefore, construct validity and reliability cannot be assessed by evaluation criteria for reflective measurement models 
[74-76]. First, we evaluated the weight, sign, and magnitude of items to assess convergent and discriminant validity following suggestions from research literature [74, 75]. Finally, we checked the multicollinearity of formative items using a variance inflation factor of less than 3.3. Based on these analyses, we conclude that the model provides a satisfactory fit and has adequate convergent validity, reliability, and discriminant validity.

For structural model, the results obtained from partial least squares (PLS) structural equation modeling (SEM) demonstrated that 1) physicians' positive evaluation of technology and their patients is linked to their intention to influence older patients' use of mobile health technology for their diabetes management, and 2) facilitating conditions for physicians and patients, directly and indirectly, affect the IT influencers' formulation of social influence. In Table 1, we report path coefficients, p-value, and effect size. According to Hair et al. (2016) [72], the assessment of structural models is generally based on three assessment criteria: $\mathrm{R}$-square measures, the level of significance of the path coefficients, and the predictive capability of the model by the Stone-Geisser's Q-square $[71,77]$.

As illustrated in Table 1, all path coefficients are statistically significant, while one path was negative and significant. More specifically, self-management practices have positive, direct impacts on assessment of others' attitudes toward the new IT use $(\beta=0.232, p=$ $0.023)$, assessment of the new IT $(\beta=0.206, p=0.015)$, and intention to influence $(\beta=0.189, p=0.006)$. Selfmanagement resources have positive, direct impacts on assessment of others' attitudes toward the new IT use ( $\beta$ $=0.173, p=0.02)$ and assessment of the new IT $(\beta=$ $0.266, \mathrm{p}=0.000$ ). Interestingly, self-management resources have a statistically significant but negative impact on intention to influence $(\beta=-0.250, p=0.000)$. Lastly, IT influencers' assessment of others' attitudes toward the new IT use and assessment of the new IT have positive impacts on intention to influence $(\beta=$ 0.421 and $\beta=0.308$, significant at $p<0.01$, respectively). The structural model explains $46 \%$ of the

Table 1. Structural model results

\begin{tabular}{|l|c|c|c|c|c|}
\hline PATH & B & $\boldsymbol{p}$ & $\boldsymbol{f}^{\boldsymbol{2}}$ & $\begin{array}{l}\text { EFFECT } \\
\text { SIZE }\end{array}$ & $\begin{array}{l}\text { SUPPORT } \\
\text { ED }\end{array}$ \\
\hline $\mathrm{SMP} \rightarrow$ ATP & 0.21 & 0.0149 & 0.05 & Small & Yes \\
\hline $\mathrm{SMP} \rightarrow$ ATT & 0.23 & 0.0226 & 0.06 & Small & Yes \\
\hline $\mathrm{SMR} \rightarrow$ ATP & 0.27 & 0.0001 & 0.07 & Small & Yes \\
\hline $\mathrm{SMR} \rightarrow$ ATT & 0.18 & 0.0204 & 0.03 & Small & Yes \\
\hline $\mathrm{SMP} \rightarrow$ ITI & 0.18 & 0.0059 & 0.05 & Small & Yes \\
\hline $\mathrm{SMR} \rightarrow$ ITI & -0.25 & 0.000 & 0.08 & Small & Yes \\
\hline $\mathrm{ATP} \rightarrow$ ITI & 0.31 & 0.0017 & 0.12 & Small & Yes \\
\hline ATT $\rightarrow$ ITI & 0.43 & 0.000 & 0.22 & Medium & Yes \\
\hline
\end{tabular}

* Total sample size was 200. variance in intention to influence ( $\mathrm{R}$-square $=0.46$ ), $18 \%$ of assessment toward primary users' IT use (Rsquare $=0.18)$, and $15 \%$ of that in attitude toward technology $(\mathrm{R}$-square $=0.344)$.

\section{Discussion}

The objective of this study was to contextualize the socially influencing behavior of non-primary IT users (IT influencers) on primary users' technology use and to examine the mechanisms as to how those individuals formulate social influence to support others' IT use. We extended the UTAUT model by linking a path of facilitating conditions and IT influencers' attitude to IT influencers' intention and further tested the mechanism through which IT influencers become motivated to guide IT use by others. We find that all hypothesized paths were statistically significant indicating that 1) IT influencers' assessment on users' capability and the technology positively influences IT influencers' social influence; 2) organizational practices supporting the task management of both IT influencers and primary IT users positively enhance IT influencers' assessment of the users and the technology, thereby positively promoting IT influencers' intention to influence.

This study extends IS use literature by reconceptualizing the role of IT observers in a social IT use context. By redefining "IT observers" as IT influencers, we identify IT influencers as a group of users whose decision-making is critical but who do not directly use the focal technology in a dyadic, social context. As organizational delegates who perform a shared task in a social environment, IT influencers interact with other users and with organizational technologies - under the influence of resources, management, strategy, and culture [79]. Under such an IT use context, IT influencers' interactions with other stakeholders and their efforts to achieve goals and perform tasks create a force of social influence. As social influence theory explains how the implicit or explicit pressures from others can modify an individual's intention to use new IT, we reveal whether and how social influence is formulated by non-primary IT users within the organizational social context of IT use. We found that IT influencers' behaviors can be promoted or prohibited by facilitating conditions and their continuous interactions with the surroundings, including the focal technology and other stakeholders.

Conversely, we also found that clinicians' evaluations of patients' attitudes about their healthcare and technology are major driving forces of social influence in healthcare. For a recent example, with increased adoption and use of telehealth technology, 
patients with varying levels of internet or health literacy are increasingly self-selecting for virtual care consultations recently [80]. Telehealth clinicians are expected to virtually examine patients, relying on personal health information presented by such patients. While physicians devise patient-specific care plans and provide directions about managing self-care, the patients' ability to recognize the quality of health information becomes non-trivial [81]. To this end, a physician's ability to assess patients concerning their understanding of health disinformation and their use of health IT is indispensable for better patient outcomes.

Interestingly, we also find that self-management resources for IT influencers (SMR) was negatively associated with IT influencers' intention to influence (ITI). Given that these self-management resources are related to physicians' involvement (e.g. providing written care plans and participation in diabetic management workshop for diabetic patients), it is likely that physicians perceived these tasks as additional workloads (Ayre et al. 2019). It would be worthwhile to further delve into this phenomenon in the future research.

Our findings should be interpreted with caution in light of the study's limitations. First, our data were collected from physicians at university hospitals in China. Prior studies have noted that cultural differences might hinder the generalizability of research findings [82]. Future research can consider exploring contextual differences of deployment of institution-introduced selfmanagement applications, examining differential patterns of physicians' social influence when recommending commercially developed selfmanagement apps, and lastly, examining other types of social influences within and beyond the boundaries of healthcare organizations. Thus, revisiting our research model in culturally richer settings might be an avenue for future research. Second, our results were derived from cross-sectional survey data. Given that crosssectional data might not fully capture changes in contextual characteristics over time, it is harder to claim a causal relationship between variables [83]. A collection of panel data could add further insights into how social influence formed by IT influencers may change over time. The limitations mentioned above can further inform the direction of future research such that identifying other contextual factors that influence the role of IT influencers would be worthwhile.

\section{Conclusion}

The current study is one of the earliest studies investigating whether and how IT influencers become activated to affect others' IT use. This paper introduces and highlights the important role of IT influencers in assessing primary IT users' readiness to use health IT for self-health management. The findings of this study suggest that IT influencers' assessment of the users and the technology concurrently affect their willingness to support the focal individuals' technology use. Furthermore, organizational support resources for both IT influencers and primary IT users enhance their ability to evaluate technology and users positively. Our findings generate new insights into the well-researched technology acceptance phenomenon and provide an enriched understanding of the mechanisms of social influence formation in a social IT use context by examining IT influencers' role and unique IT-directed behavior, intention to influence.

\section{References}

[1] Griffin RK, Baldwin D, Sumichrast RT. "SelfManagement Information System for the Service Industry: A Conceptual Model". Journal of Management Information Systems. 1994;10(4):111-33.

[2] Barrett AK, Stephens KK. "Making electronic health records (EHRs) work: informal talk and workarounds in healthcare organizations". Health Commun. 2017;32(8):100413.

[3] Kimes SE, Collier JE. "How customers view self-service technologies". MIT Sloan Management Review. 2015;57(1):25.

[4] Speier C, Venkatesh V. "The hidden minefields in the adoption of sales force automation technologies". Journal of Marketing. 2002;66(3):98-111.

[5] Ahuja MK, Chudoba KM, Kacmar CJ, McKnight DH, George JF. "IT road warriors: Balancing work-family conflict, job autonomy, and work overload to mitigate turnover intentions". Mis Quarterly. 2007:1-17.

[6] Hunt CW. "Technology and diabetes self-management: an integrative review". World journal of diabetes. 2015;6(2):225. [7] Boyle L, Grainger R, Hall RM, Krebs JD. "Use of and beliefs about mobile phone apps for diabetes selfmanagement: surveys of people in a hospital diabetes clinic and diabetes health professionals in New Zealand". JMIR mHealth and uHealth. 2017;5(6).

[8] Schmitz J, Fulk J. "Organizational colleagues, media richness, and electronic mail: A test of the social influence model of technology use". Communication research. 1991;18(4):487-523.

[9] Venkatesh V, Morris MG, Davis GB, Davis FD. "User acceptance of information technology: Toward a unified view". MIS quarterly. 2003:425-78.

[10] Sergeeva A, Huysman M, Soekijad M, van den Hooff B. "Thorugh the eyes of others: how onlookers shape the use of technology at work". MIS Quarterly. 2017;41(4).

[11] Farshadkhah S, Van Slyke C, Fuller B. "Onlooker effect and affective responses in information security violation mitigation". Computers \& Security. 2021;100:102082.

[12] Pollock N, Hyysalo S. "The business of being a user: The role of the reference actor in shaping packaged enterprise 
system acquisition and development". MIS quarterly. 2014;38(2):473-96.

[13] Oborn E, Barrett M, Davidson E. "Unity in diversity: Electronic patient record use in multidisciplinary practice". Information Systems Research. 2011;22(3):547-64.

[14] LeRouge CM, Hah H, Deckard GJ, Jiang H. "Designing for the Co-Use of Consumer Health Technology in SelfManagement of Adolescent Overweight and Obesity: Mixed Methods Qualitative Study". JMIR Mhealth Uhealth. 2020;8(6):e18391.

[15] Venkatesh V. "Adoption and use of AI tools: a research agenda grounded in UTAUT". Annals of Operations Research. 2021:1-12.

[16] Jadil Y, Rana NP, Dwivedi YK. "A meta-analysis of the UTAUT model in the mobile banking literature: The moderating role of sample size and culture". Journal of Business Research. 2021;132:354-72.

[17] Venkatesh V, Thong JY, Xu X. "Unified theory of acceptance and use of technology: A synthesis and the road ahead". 2016.

[18] Fulk J, Steinfield CW, Schmitz J, Power JG. "A social information processing model of media use in organizations". Communication research. 1987;14(5):529-52.

[19] Nicolini D. "Practice as the Site of Knowing: Insights from the Field of Telemedicine". Organization Science. 2011;22(3):602-20.

[20] Salancik GR, Pfeffer J. "A Social Information Processing Approach to Job Attitudes and Task Design". Administrative Science Quarterly. 1978;23(2):224-53.

[21] Bagozzi RP, Lee K-H. "Multiple Routes for Social Influence: The Role of Compliance, Internalization, and Social Identity". Social Psychology Quarterly. 2002;65(3):226-47.

[22] Amabile TM, Conti R, Coon H, Lazenby J, Herron M. "Assessing the work environment for creativity". Academy of management journal. 1996;39(5):1154-84.

[23] Ahuja MK, Thatcher JB. "Moving beyond intentions and toward the theory of trying: effects of work environment and gender on post-adoption information technology use". MIS quarterly. 2005;29(3):427-59.

[24] Orlikowski WJ. "The duality of technology: Rethinking the concept of technology in organizations". Organization science. 1992;3(3):398-427.

[25] Fulk J, Schmitz J, Steinfield CW. "A social influence model of technology use". Organizations and communication technology. 1990;117:140.

[26] Bandura A. "The explanatory and predictive scope of selfefficacy theory". Journal of social and clinical psychology. 1986;4(3):359-73.

[27] Bandura A. Model of causality in social learning theory. Cognition and psychotherapy: Springer; 1985. p. 81-99.

[28] Brown SA, Venkatesh V. "Model of adoption of technology in households: A baseline model test and extension incorporating household life cycle". MIS quarterly. 2005:399426.

[29] Fulk J. "Social construction of communication technology". Academy of Management journal. 2017.

[30] Sarker S, Valacich JS, Sarker S. "Technology adoption by groups: A valence perspective". Journal of the Association for Information Systems. 2005;6(2):3.
[31] Leonardi PM. "When does technology use enable network change in organizations? A comparative study of feature use and shared affordances". MIS quarterly. 2013:74975.

[32] Venkatesh V, Morris MG. "Why don't men ever stop to ask for directions? Gender, social influence, and their role in technology acceptance and usage behavior". MIS quarterly. 2000:115-39.

[33] Kohli R, Kettinger WJ. "Informating the clan: Controlling physicians' costs and outcomes". Mis Quarterly. 2004:363-94. [34] Liang H, Xue YL, Ke W, Wei KK. "Understanding the influence of team climate on IT use". Journal of the Association for Information Systems. 2010;11(8):2.

[35] Sarker S, Valacich JS. "An alternative to methodological individualism: A non-reductionist approach to studying technology adoption by groups". Mis Quarterly. 2010:779808.

[36] Boynton AC, Zmud RW, Jacobs GC. "The influence of IT management practice on IT use in large organizations". MIS quarterly. 1994:299-318.

[37] Tallon PP, Kraemer KL, Gurbaxani V. "Executives' perceptions of the business value of information technology: a process-oriented approach". Journal of management information systems. 2000;16(4):145-73.

[38] Armstrong CP, Sambamurthy V. "Information technology assimilation in firms: The influence of senior leadership and IT infrastructures". Information systems research. 1999;10(4):304-27.

[39] Neufeld DJ, Dong L, Higgins C. "Charismatic leadership and user acceptance of information technology". European Journal of Information Systems. 2007;16(4):494-510.

[40] Subramani M. "How do suppliers benefit from information technology use in supply chain relationships?". MIS quarterly. 2004:45-73.

[41] Isaksson $\mathrm{OH}$, Simeth M, Seifert RW. "Knowledge spillovers in the supply chain: Evidence from the high tech sectors". Research Policy. 2016;45(3):699-706.

[42] Rai A, Patnayakuni R, Seth N. "Firm performance impacts of digitally enabled supply chain integration capabilities". MIS quarterly. 2006:225-46.

[43] Bhattacherjee A, Sanford C. "Influence processes for information technology acceptance: An elaboration likelihood model". MIS quarterly. 2006:805-25.

[44] Chiu C-M, Huang H-Y, Cheng H-L, Hsu Jack S-C. "Driving individuals' citizenship behaviors in virtual communities through attachment". Internet Research. 2019;29(4):870-99.

[45] WHO. Innovative Care for Chronic Conditions: Building Blocks for Action. In: Organizations WH, editor. 2002.

[46] Alkenizan A. "Innovative care for chronic conditions: building blocks for action". Ann Saudi Med Ann Saudi Med. 2004;24(2):148-.

[47] Yi MY, Jackson JD, Park JS, Probst JC. "Understanding information technology acceptance by individual professionals: Toward an integrative view". Information \& Management. 2006;43(3):350-63.

[48] Garvare R, Johansson P. "Management for sustainabilitya stakeholder theory". Total quality management. 2010;21(7):737-44. 
[49] Freeman RE, Reed DL. "Stockholders and stakeholders: A new perspective on corporate governance". California management review. 1983;25(3):88-106.

[50] Freeman RE. "Divergent stakeholder theory". Academy of management review. 1999;24(2):233-6.

[51] Foley KJ. Meta management: A stakeholder/quality management approach to whole-of-enterprise management: Standards Australia; 2005.

[52] Reimann M, Schilke O, Thomas JS. "Customer relationship management and firm performance: the mediating role of business strategy". Journal of the academy of marketing science. 2010;38(3):326-46.

[53] Rai A, Chen L, Pye J, Baird A. "Understanding determinants of consumer mobile health usage intentions, assimilation, and channel preferences". Journal of medical Internet research. 2013;15(8).

[54] Serrano CI, Karahanna E. "The Compensatory Interaction Between User Capabiities and Technology Capabilities in Influencing Task Performance: An Empirical Assessment in Telemedicine Consultations". MIS Quarterly. 2016;40(3):597-621.

[55] Gerber BS, Eiser AR. "The patient-physician relationship in the Internet age: future prospects and the research agenda". Journal of medical Internet research. 2001;3(2).

[56] Tan SS-L, Goonawardene N. "Internet health information seeking and the patient-physician relationship: a systematic review". Journal of medical Internet research. 2017;19(1).

[57] Schillinger D, Piette J, Grumbach K, Wang F, Wilson C, Daher C, et al. "Closing the Loop: Physician Communication With Diabetic Patients Who Have Low Health Literacy". Archives of Internal Medicine. 2003;163(1):83-90.

[58] Coughlin SS, Stewart JL, Young L, Heboyan V, De Leo G. "Health literacy and patient web portals". International Journal of Medical Informatics. 2018;113:43-8.

[59] Hah H, Goldin D, Ha S. "The Association Between Willingness of Frontline Care Providers' to Adaptively Use Telehealth Technology and Virtual Service Performance in Provider-to-Provider Communication: Quantitative Study". Journal of medical Internet research. 2019;21(8):e15087.

[60] Kennedy A, Gask L, Rogers A. "Training professionals to engage with and promote self-management". Health Education Research. 2005;20(5):567-78.

[61] Davis FD. "Perceived usefulness, perceived ease of use, and user acceptance of information technology". MIS quarterly. 1989:319-40.

[62] Orlikowski WJ, Iacono CSJIsr. "Research commentary: Desperately seeking the "IT" in IT research-A call to theorizing the IT artifact". 2001;12(2):121-34.

[63] Min J, Yoo Y, Hah H, Lee H. "Social network technology (SNT) as a tool and a social actor: from self-verification to SNT use". Internet Research. 2020.

[64] Gruessner V. Only 15\% of Doctors Recommend Mobile Health Apps to Patients. mHealth Intelligence. 2015.

[65] Li Y, Teng D, Shi X, Qin G, Qin Y, Quan H, et al. "Prevalence of diabetes recorded in mainland China using 2018 diagnostic criteria from the American Diabetes Association: national cross sectional study". BMJ. 2020;369:m997.

[66] Yang W, Lu J, Weng J, Jia W, Ji L, Xiao J, et al. "Prevalence of Diabetes among Men and Women in China". New England Journal of Medcine. 2010;362:1090-101.
[67] Yung CY, Tse SLS, Chan KSY, Chow CKC, Yau CWS, Chan TYK, et al. "Age-Related Decline in the Knowledge of Diabetes Mellitus and Hypoglycaemic Symptoms in NonInsulin-Dependent Diabetic Patients in Hong Kong". Age Ageing. 1998;27(3):327-32.

[68] China NBoSo. China: mobile phone subscriptions by month 2020-2021 In: China NBoSo, editor. 2021.

[69] Cheng E. China says it now has nearly 1 billion internet users. CNBC. 2021.

[70] Venkatesh VJIsr. "Determinants of perceived ease of use: Integrating control, intrinsic motivation, and emotion into the technology acceptance model". 2000;11(4):342-65.

[71] Hair JF, Sarstedt M, Ringle CM, Mena JA. "An assessment of the use of partial least squares structural equation modeling in marketing research". Journal of the academy of marketing science. 2012;40(3):414-33.

[72] Hair Jr JF, Hult GTM, Ringle C, Sarstedt M. A primer on partial least squares structural equation modeling (PLS-SEM): Sage publications; 2016.

[73] Malhotra NK, Kim SS, Patil A. "Common method variance in IS research: A comparison of alternative approaches and a reanalysis of past research". Management science. 2006;52(12):1865-83.

[74] Petter S, Straub D, Rai A. "Specifying Formative Constructs in Information Systems Research". MIS Quarterly. 2007;31(4):623-56.

[75] Henseler J, Chin WW. "A comparison of approaches for the analysis of interaction effects between latent variables using partial least squares path modeling". Structural Equation Modeling. 2010;17(1):82-109.

[76] MacKenzie SB, Podsakoff PM, Podsakoff NP. "Construct measurement and validation procedures in MIS and behavioral research: Integrating new and existing techniques". MIS quarterly. 2011;35(2):293-334.

[77] Geisser S. "A predictive approach to the random effect model". Biometrika. 1974;61(1):101-7.

[78] Heisey-Grove DM. "Variation In Rural Health Information Technology Adoption And Use". Health Aff. 2016;35(2):365-70.

[79] Orlikowski WJ. "Knowing in practice: Enacting a collective capability in distributed organizing". Organization science. 2002;13(3):249-73.

[80] Gray DM, II, Joseph JJ, Olayiwola JN. "Strategies for Digital Care of Vulnerable Patients in a COVID-19 WorldKeeping in Touch". JAMA Health Forum. 2020;1(6):e200734-e.

[81] Schulz PJ, Pessina A, Hartung U, Petrocchi S. "Effects of Objective and Subjective Health Literacy on Patients' Accurate Judgment of Health Information and DecisionMaking Ability: Survey Study". J Med Internet Res. 2021;23(1):e20457.

[82] Chai L, Pavlou PA. "From "ancient" to "modern": a crosscultural investigation of electronic commerce adoption in Greece and the United States". Journal of Enterprise Information Management. 2004.

[83] Wooldridge JM. Econometric analysis of cross section and panel data: MIT press; 2010.

[84] Nunes F, Verdezoto N, Fitzpatrick G, Kyng M, Grönvall E, Storni C. "Self-Care Technologies in HCI: Trends, Tensions, and Opportunities". ACM Trans Comput-Hum Interact. 2015;22(6):Article 33. 